\title{
Infrared Absorption Spectra of Five Halomethanes
}

\author{
Earle K. Plyler and Nicolo Acquista
}

\begin{abstract}
The infrared absorption spectra of five halomethanes, bromodifluoromethane, dibromodifluoromethane, bromochlorodifluoromethane, bromotrifluoromethane, and iodotrifluoromethane have been studied from 2 to 38 microns. Fundamental, combination, overtone, and difference bands have been identified. Many unobserved fundamentals have been predicted by comparisons with related molecules and with Raman spectra. The fundamentals have been classified as to the type of motion and the principal atom involved. Four tables are included to show the relationships among the fundamentals of the molecules compared.
\end{abstract}

\section{Introduction}

The infrared spectra of bromodifluoromethane, dibromodifluoromethane, bromochlorodifluoromethane, bromotrifluoromethane, and iodotrifluoromethane have been measured from 2 to $38 \mu$. The purpose of the measurements was to identify the fundamentals and to classify them as to their modes of vibration. The resulting classification allows a comparison of the vibrations of these molecules with other related substituted methanes studied by other investigators [1]. ${ }^{1} \quad$ Recently Decius subjected many methane derivatives to a normal coordinate treatment and quantitatively verified the experimental assignments [2]. Plyler and Benedict extended the calculations of Decius and were able to check some of the assignments of the molecules they studied [3]. In addition, the Raman spectra of the molecules have been investigated [4].

\section{Instrumentation}

A double-beam Perkin-Elmer model 21 spectrophotometer measured the compounds from 2 to $15 \mu$, and a single-beam Perkin-Elmer spectrometer extended the measurements from 15 to $38 \mu$. A KBr prism was used from 15 to $23 \mu$ and a TlBr-I prism from 23 to $38 \mu$.

For most of the measurements from 2 to $23 \mu$, a 5 -cm gas cell with pressures of $1 \mathrm{~atm}$ or less was used. In order to detect some of the weak absorption bands, two cells of 40- and 130-cm lengths were employed. These two cells could not be evacuated. They were filled by flowing gases through them.

The five compounds were supplied by R. C. McHarness of the Jackson Laboratories. Tests made by the Bureau's Mass Spectrometry Section indicated minute traces of foreign halogenatedmethanes in four of the compounds. Only $\mathrm{CBr}_{2} \mathrm{~F}_{2}$ had impurities in slight excess of 3 percent. These impurities were not observed in the $\mathrm{CBr}_{2} \mathrm{~F}_{2}$ spectrum, probably because they were masked by the strong absorption bands of the molecule.

\section{Results}

Figure 1 shows the absorption spectra of $\mathrm{CHBrF}_{2}$, $\mathrm{CBr}_{2} \mathrm{~F}_{2}$, and $\mathrm{BrClF}_{2}$ in the region from 2 to $15 \mu$. The cell length was $5 \mathrm{~cm}$ for all measurements. The

${ }_{1}$ Figures in brackets indicate the literature references at the end of this paper. pressure used is indicated on the graph. It is seen that pressures as low as $0.01 \mathrm{~cm}$ of $\mathrm{Hg}$ were necessary to resolve the structures of the strongest bands. In some cases, it is possible to tell from the graph whether the bands have $\mathrm{P}, \mathrm{Q}$, and R, or only $\mathrm{P}$ and $\mathrm{R}$ branches.

Figure 2 shows the abosorption spectra of $\mathrm{CBrF}_{3}$ and $\mathrm{CIF}_{3}$ from 2 to $15 \mu$. The pressures of the gases are indicated next to the respective traces. The cell length employed was also $5 \mathrm{~cm}$. The curves in figures 1 and 2 are traces from the original record obtained from the double-beam spectrophotometer. These graphs have not been corrected for surface reflection of the cells or for stray radiation in the instrument. However, a reflection filter was used beyond $9.2 \mu$, and as a consequence, the stray radiation did not exceed 5 percent at any wavelength.

Figure 3 shows the infrared absorption spectra of the five compounds in the region from 14 to $36 \mu$. These measurements were extended to $38 \mu$, but no bands were observed beyond $36 \mu$. These compounds were measured in the gaseous state, using cells of 5,40 , and $130 \mathrm{~cm}$ in length. The pressures, where measureable, are indicated on the graph. Attempts were made to examine the spectra of these molecules as a liquid because many of the fundamentals did not appear in the gaseous state. However, due to the high volatility of all the compounds at room temperature, only $\mathrm{CBr}_{2} \mathrm{~F}_{2}$ could be measured in this manner. A liquid cell with a thickness 1.5 mm was used for these measurements. The portion of the curves drawn in broken lines indicates that weak absorption bands could not be observed because of atmospheric bands. Table 1 gives a list of wavelengths of all the bands that appear in the infrared. In addition, there are listed bands that do not appear either because their intensity is too weak or because they fall outside the wavelength region studied. These frequencies are taken either from the Raman spectra or from overtone and combination bands. Some of these frequencies have also been predicted by comparison with analogous halomethanes. When a band has been sufficiently resolved by the prism spectrometers, the $\mathrm{P}, \mathrm{Q}$, and $\mathrm{R}$, or $\mathrm{P}$ and $\mathrm{R}$ branches have been listed separately. The intensities are indicated adjacent to the respective band, and these are denoted by abbreviations of very weak, weak, medium, strong, and very strong. The fundamentals have been designated by the numbering system proposed by Plyler and Benedict [3]. Using 
this notation, it is possible to see the regularities that exist among related molecules of different symmetry. Another way of denoting the fundamentals, which was also used, is to characterize them by the molecular motion involved. In this system, $\nu_{x}$ represents the stretching vibration between the central carbon and the $\mathrm{X}$ atoms, and $\delta_{x}$ signifies the bending of the $\mathrm{X}$ atom against the rest of the molecule.
The number of fundamentals expected in these molecules can be predicted, as is well known, from symmetry considerations. The five compounds can be put into three point groups. $\mathrm{CBrClF}_{2}$ and $\mathrm{CHBrF}_{2}$ have only one plane of symmetry (the $\mathrm{CBrCl}$ and $\mathrm{CHBr}$ plane, respectively), and thus belong to the point group $\mathrm{C}_{\mathrm{s}}$, whereas $\mathrm{CBr}_{2} \mathrm{~F}_{2}$ has two symmetry planes, placing it in $\mathrm{C}_{2 \mathrm{v}}$. The molecules $\mathrm{CBrF}_{3}$ and $\mathrm{CIF}_{3}$ have a threefold axis of sym-

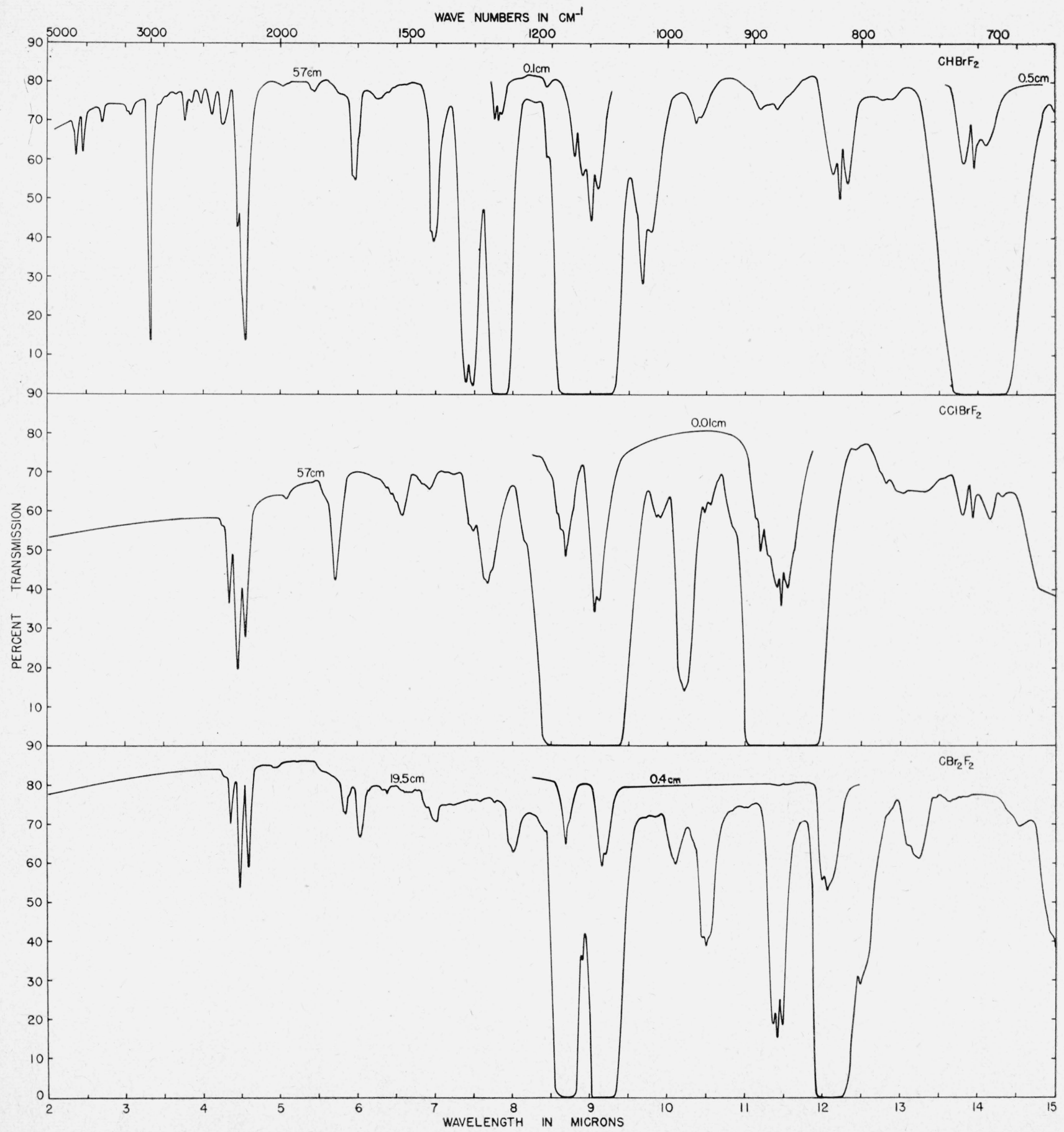

FIGURE 1. Infrared absorption spectra of bromodifluoro-methane, bromochlorodifluoromethane, dibromodifluoromethane from 2 to $15 \mu$. 
TABLE 1. Classification of the infrared bands of bromodifluoromethane, bromochlorodifluoromethane, dibromodifluoromethane, bromotrifluoromethane, and iodotrifluoromethane

\begin{tabular}{|c|c|c|c|c|c|}
\hline$\lambda$ & $\nu$ & I & \multicolumn{3}{|c|}{ Assignments } \\
\hline \multicolumn{6}{|c|}{$\mathrm{CHBrF}_{2}$} \\
\hline $\begin{array}{l}\mu \\
\text { 3. } 33 \\
7.40 \mathrm{R} \\
7.44 \mathrm{P} \\
7.48 \mathrm{P} \\
7.76 \mathrm{R} \\
7.81 \mathrm{Q} \\
7.85 \mathrm{P} \\
8.81 \\
8.90 \mathrm{R} \\
9.02 \mathrm{Q} \\
9.10 \mathrm{P} \\
13.82 \mathrm{R} \\
13.93 \mathrm{Q} \\
14.12 \mathrm{P} \\
17.11 \mathrm{R} \\
17.34 \mathrm{Q} \\
17.48 \mathrm{P} \\
31.0 \\
41.6 \\
2.36 \\
2.45 \\
2.69 \\
3.06 \\
3.76 \\
3.83 \\
3.96 \\
4.10 \\
4.25 \\
4.44 \\
4.55 \\
5.03 \\
5.19 \\
5.97 \\
6.25 \\
6.97 \\
8.44 \\
9.68 \\
10.37 \\
11.20 \\
11.42 \\
12.14 \mathrm{R} \\
12.22 \mathrm{Q} \\
12.34 \mathrm{P} \\
15.52\end{array}$ & $\begin{array}{l}\mathrm{Cm}^{-1} \\
3003 \\
1351 \\
1344 \\
1337 \\
1289 \\
1280 \\
1274 \\
1135 \\
1123 \\
1108 \\
1099 \\
724 \\
718 \\
708 \\
584 \\
577 \\
572 \\
323 \\
240 \\
4237 \\
4080 \\
3716 \\
3267 \\
2659 \\
2610 \\
2525 \\
2438 \\
2352 \\
2252 \\
2197 \\
1983 \\
1926 \\
1675 \\
1600 \\
1434 \\
1185 \\
1033 \\
964 \\
893 \\
875 \\
824 \\
818 \\
810 \\
644\end{array}$ & $\begin{array}{c}\text { S } \\
s \\
s \\
s \\
\end{array}$ & $\begin{array}{l}\omega_{1} \\
\omega_{8} \\
\omega_{6} \\
\omega_{3} \\
\omega_{4} \\
\omega_{7} \\
\omega_{9} \\
\omega_{5} \\
\omega_{2} \\
\omega_{6}+\omega_{1} \\
\omega_{3} \mu_{1} \\
\omega_{7}+\omega_{1} \\
\omega_{2}+\omega_{1} \\
2 \omega_{8} \\
\omega_{8}+\omega_{6} \\
2 \omega_{6} \\
\omega_{8}+\omega_{9} \\
2 \omega_{3} \\
\omega_{3}+\omega_{9} \\
2 \omega_{9} \\
\omega_{7}+\omega_{6} \\
\omega_{8}+\omega_{4} \\
\omega_{4}+\omega_{9}, \omega_{5}+\omega_{8} \\
\omega_{2}+\omega_{8}, \omega_{5}+\omega_{6} \\
2 \omega_{7} \\
2 \omega_{4} \\
\omega_{5}+\omega_{7} \\
\omega_{2}+\omega_{7} \\
\omega_{4}+\omega_{5} \\
\\
\omega_{2}+\omega_{4} \\
2 \omega_{5}\end{array}$ & . & . \\
\hline \multicolumn{6}{|c|}{$\mathrm{CBr}_{2} \mathrm{~F}_{2}$} \\
\hline $\begin{array}{c}9.15 \mathrm{R} \\
9.19 \\
9.21 \mathrm{P} \\
8.69 \mathrm{Q} \\
12.06 \mathrm{Q} \\
16.03 \mathrm{R} \\
16.10 \mathrm{P} \\
16.18 \mathrm{P} \\
29.4 \\
27.2 \\
30.2 \\
35.5 \\
60.6 \\
4.37 \\
4.50 \\
4.60 \\
5.85 \\
6.05 \\
6.90 \\
7.00 \\
8.00 \\
8.91 \\
10.10 \\
10.45 \mathrm{R} \\
10.50 \mathrm{Q} \\
10.55 \mathrm{P} \\
10.96 \mathrm{P} \\
11.37 \mathrm{R} \\
11.43 \mathrm{Q} \\
11.49 \mathrm{P} \\
12.49 \\
13.19 \\
13.75 \\
14.54 \\
15.10 \\
20.90\end{array}$ & $\begin{array}{r}1093 \\
1088 \\
1086 \\
1150 \\
829 \\
624 \\
621 \\
618 \\
\text { b } 340 \\
\text { b } 367 \\
\text { c } 331 \\
\text { b } 282 \\
\text { b } 165 \\
2288 \\
2222 \\
2173 \\
1709 \\
1652 \\
1449 \\
1428 \\
1250 \\
1122 \\
990 \\
957 \\
952 \\
948 \\
912 \\
880 \\
875 \\
870 \\
800 \\
758 \\
727 \\
688 \\
662 \\
478\end{array}$ & 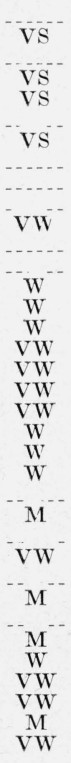 & $\begin{array}{l}\omega_{1} \\
\omega_{8} \\
\omega_{6} \\
\omega_{3} \\
\omega_{4} \\
\omega_{9} \\
\omega_{7} \\
\omega_{5} \\
\omega_{2} \\
2 \omega_{8} \\
\omega_{8}+\omega_{1} \\
2 \omega_{1} \\
\omega_{1}+\omega_{3} \\
2 \omega_{6} \\
\omega_{6}+\omega_{3} \\
\omega_{7}+\omega_{1} \\
2 \omega_{3} \\
\omega_{6}+\omega_{5} \\
3 \omega_{7}, \omega_{2}+\omega_{6} \\
\omega_{7}+\omega_{3} \\
\omega_{5}+\omega_{3} \\
\omega_{8}-\omega_{5} \\
\omega_{3}+\omega_{2} \\
\omega_{1}-\omega_{7} \\
\omega_{1}-\omega_{9} \\
2 \omega_{4} \\
2 \omega_{7} \\
\omega_{6}-\omega_{7}, \omega_{2}+\omega_{7}\end{array}$ & & \\
\hline
\end{tabular}

See footnotes at end of table.
TABLE 1. Classification of the infrared bands of bromodifluoromethane, bromochlorodifluoromethane, dibromodifuoromethane, bromotrifluoromethane, and iodotrifluoromethaneContinued

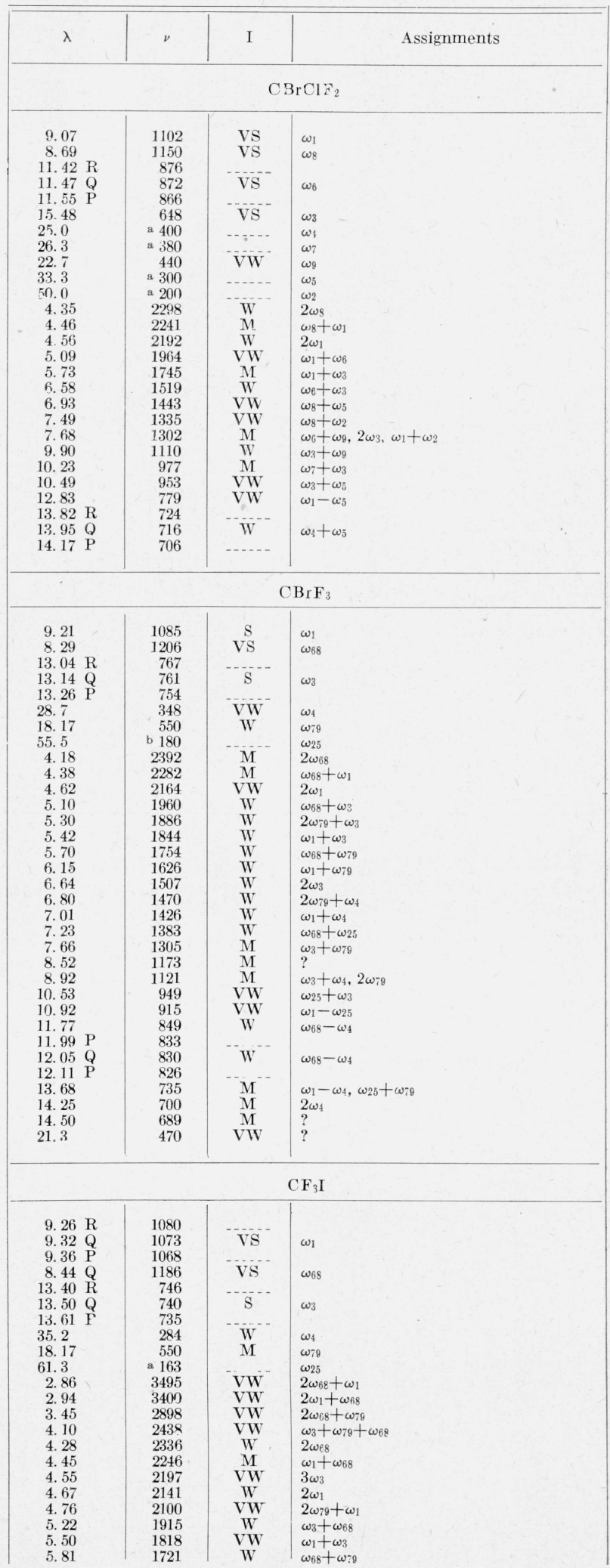


TABLE 1. Classification of the infrared bands of bromcdifluoromethane, bromochlorodifluoromethane, dibromcdifluoromethane, bromotrifluoromethane, and icdctriflucromethaneContinued

\begin{tabular}{|c|c|c|c|}
\hline$\lambda$ & $\nu$ & I & Assignments \\
\hline \multicolumn{4}{|c|}{$\mathrm{CF}_{3} \mathrm{I}-\mathrm{Continued}$} \\
\hline $\begin{array}{l}6.23 \\
6.93 \\
7.52 \\
8.02 \\
8.97 \mathrm{Q} \\
9.70 \mathrm{R} \\
9.75 \mathrm{Q} \\
9.80 \mathrm{P} \\
10.91 \\
12.18 \\
12.87 \\
14.05 \\
22.30\end{array}$ & $\begin{array}{r}1605 \\
1443 \\
1329 \\
1246 \\
1114 \\
1031 \\
1025 \\
1020 \\
916 \\
820 \\
776 \\
711 \\
448\end{array}$ & $\begin{array}{c}\text { W } \\
\text { VW } \\
\text { W } \\
\text { M } \\
\text { W } \\
M \\
\text { M } \\
\text { VW } \\
\text { W } \\
\text { VW } \\
\text { VW } \\
\text { W }\end{array}$ & $\begin{array}{l}\omega_{1}+\omega_{79} \\
2 \omega_{3} . \omega_{4}+\omega_{68} \\
\omega_{68}+\omega_{25} \\
\omega_{1}+\omega_{25} \\
2 \omega_{79} \\
\omega_{3}+\omega_{4} \\
\omega_{1}-\omega_{25}, \omega_{25}-\omega_{3} \\
\omega_{4}+\omega_{79} \\
\omega_{1}-\omega_{4} \\
\omega_{25}+\omega_{79} \\
\omega_{4}+\omega_{15}\end{array}$ \\
\hline
\end{tabular}

a Predicted from combination and overtone binds.

b Raman value.

c Liquid.

metry and three planes of symmetry. Therefore they belong to the point group $\mathrm{C}_{3 \mathrm{v}}$. Molecules in the point group $\mathrm{C}_{3 \mathrm{v}}$ have six different active fundamentals, whereas those in $\mathrm{C}_{2 \mathrm{v}}$ and $\mathrm{C}_{\mathrm{s}}$ have nine, one of which $\omega_{5}$, is theoretically inactive in the infrared, but which is actually found in this type of molecule.
Six methods were used to identify and classify the fundamental vibrations of the five halomethanes, as follows: (1) comparison with available Raman spectra; (2) comparison with the calculated values of Stepanov [5]; (3) comparison with similar molecules, that is, isotope effect; (4) calculation based on overtone and combination bands; (5) intensity considerations; and (6) consideration of band envelopes.

In table 2 are shown the nine infrared fundamental frequencies of $\mathrm{CHBrF}_{2}$. These are compared with the calculated values of Stepanov and with the assigned fundamentals of $\mathrm{CHClF}_{2}$. Of eight fundamentals found in the infrared, seven give rise to strong bands. Stepanov estimates that his calculated values are accurate to within 30 to $50 \mathrm{~cm}^{-1}$. Six of the nine fundamentals fall within this accuracy. The classification of $\mathrm{CHBrF}_{2}$, as to the modes of motion and the main atom involved, is based on the assignments of the related molecule $\mathrm{CHClF}_{2}$. Six of the fundamentals should have almost the same value for the two molecules, as they involve primarily the motions of the same atoms. The other three vibrations, $\nu_{\mathrm{Br}}, \delta_{\mathrm{FBr}}$, and $\delta_{\mathrm{Br}}$, should all occur at smaller wave numbers than the corresponding vibration $\nu_{\mathrm{Cl}}, \delta_{\mathrm{FCl}}$, and $\delta_{\mathrm{Cl}}$. This is the case for the

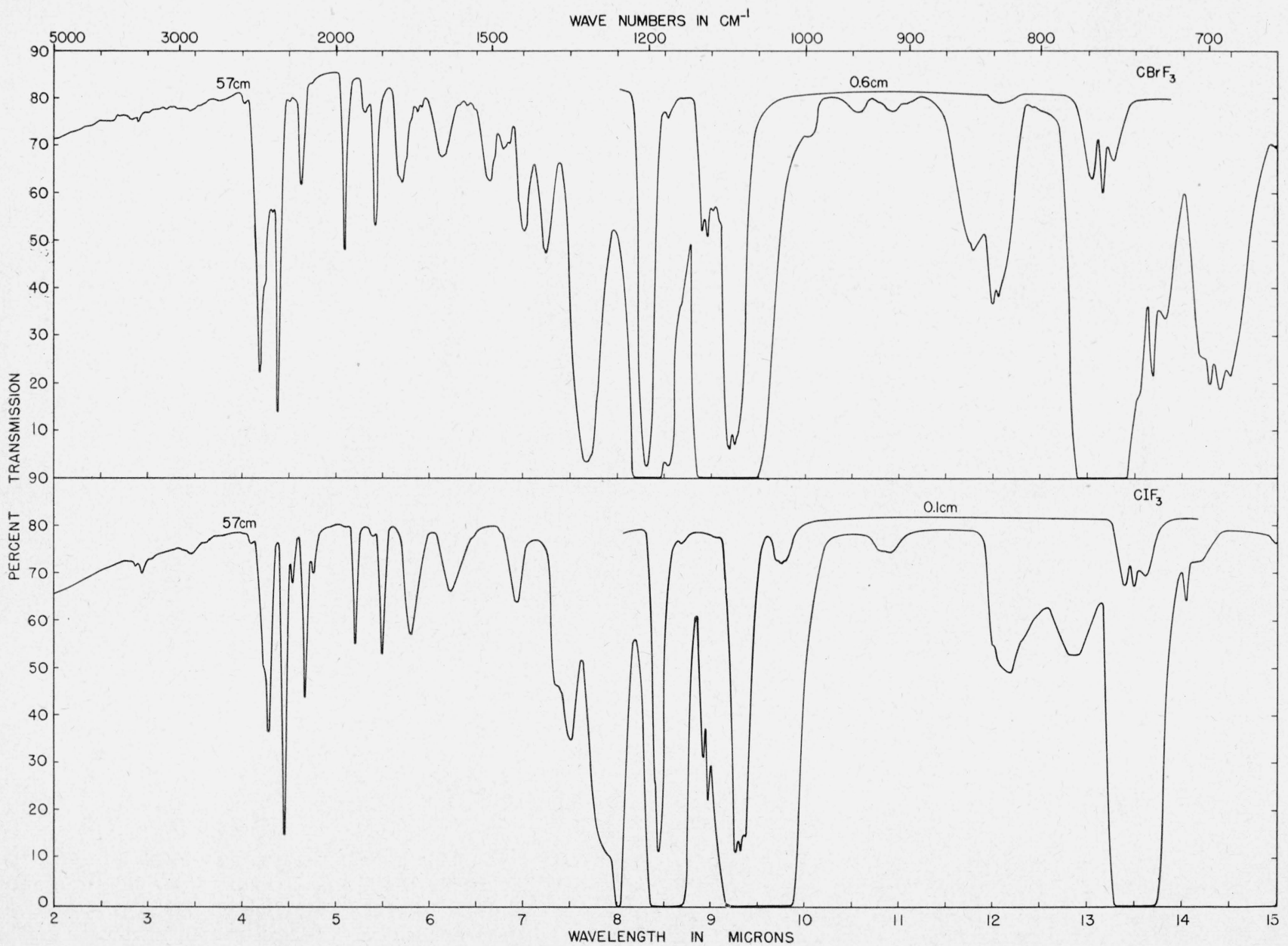

FIGURE 2. Absorption spectra of bromotrifluoromethane and iodotrifluoromethane from 2 to $15 \mu$. 


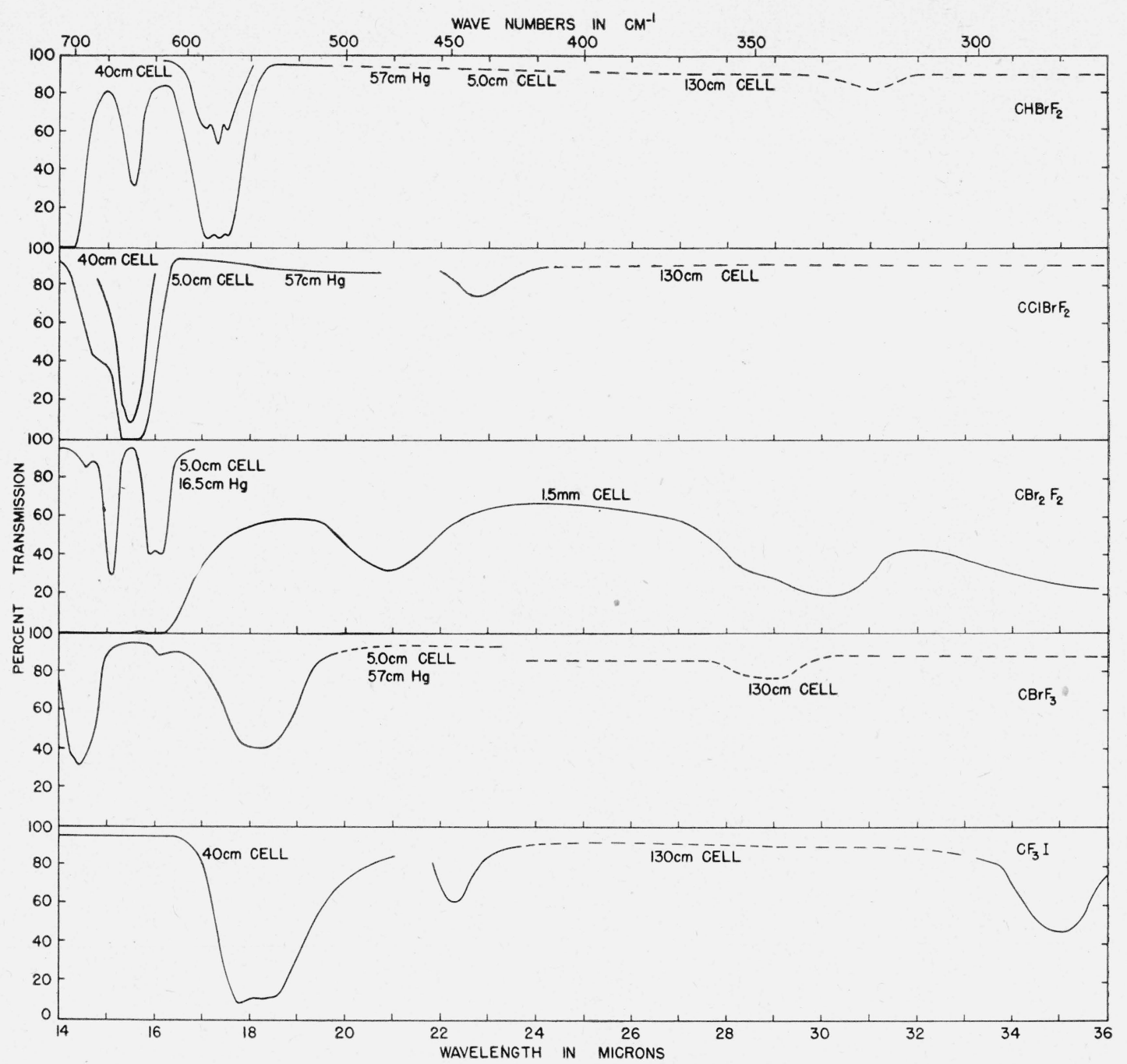

FIGURE 3. Infrared absorption spectra of bromodifluoromethane, bromochlorodifluoromethane, dibromodifluoromethane, bromotrifluoromethane, and iodotrifluoromethane from 14 to $36 \mu$.

assignments in table 2 . The frequency, $240 \mathrm{~cm}^{-1}$, which was outside the TIBr-I region, was determined from the combination bands. The value $240 \mathrm{~cm}^{-1}$ for $\omega_{2}$ seems more probable for the bending vibration of bromine than the calculated value of the $320 \mathrm{~cm}-{ }^{1}$ when related molecules are considered.

TABLE 2. Infrared fundamentals of bromodifluoromethane compared with the fundamentals of chlorodifluoromethane and with the calculated values of Stepanov

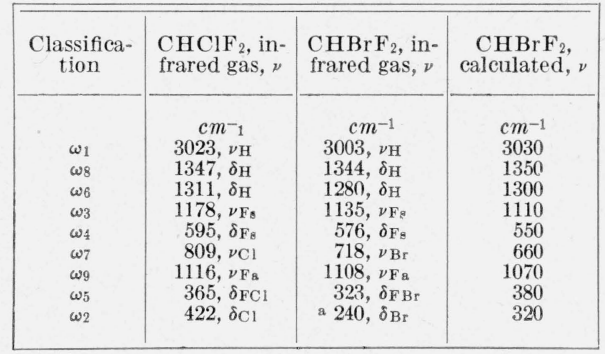

a Predicted from combination and overtone bands.
The six fundamentals of $\mathrm{CBrF}_{3}$ and $\mathrm{CF}_{3} \mathrm{I}$ have been accounted for by a comparison with the calculated values of $\mathrm{CBrF}_{3}$ of Stepanov and with the fundamental frequencies of the related symmetric top molecule $\mathrm{CClF}_{3}$ previously studied. Five of the fundamentals of $\mathrm{CBrF}_{3}$ and $\mathrm{CF}_{3} \mathrm{I}$ fall within the spectral region measured. The sixth fundamental, $\omega_{25}$, was determined from the calculated value for $\mathrm{CBrF}_{3}$, and for $\mathrm{CF}_{3} \mathrm{I}$ it was determined from the combination bands. The $\nu_{\mathrm{Fs}}, \nu_{\mathrm{Fa}}$, and $\delta_{\mathrm{Fa}}$ vibrations of the three molecules have almost the same frequencies. It is somewhat unusual that the vibrations $\nu_{\mathrm{Cl}}, \nu_{\mathrm{Br}}$, and $\nu_{\mathrm{I}}$ are almost equal. This effect may be produced by the small $\mathrm{C}-\mathrm{F}$ distances in these molecules. The intensities of $\omega_{4}$ and $\omega_{79}$, the $\delta_{\mathrm{F}}$ for both compounds, are very weak. This appears to be typical of this vibration and is found to occur in similar fluoromethanes. The selection of these two frequencies as fundamentals seems justifiable on the basis of the overtone and combination bands. Table 3 also shows that the effect of replacing a chlorine by 
TABLE 3. Comparison of the fundamentals of bromotrifuoromethane and iodotrifluoromethane with the infrared fundamentals of chlorotrifluoromethane and with the calculated fundamentals of Stepanov.

\begin{tabular}{|c|c|c|c|c|}
\hline $\begin{array}{l}\text { Classifi- } \\
\text { cation }\end{array}$ & $\begin{array}{c}\mathrm{CClF}_{3}, \\
\text { infrared } \\
\text { gas, } \nu\end{array}$ & $\begin{array}{c}\mathrm{CBrF}_{3}, \text { in- } \\
\text { frared } \\
\text { vapor, } \nu\end{array}$ & $\begin{array}{l}\mathrm{CBrF}_{3}, \\
\text { a calcu- } \\
\text { lated, } \nu\end{array}$ & $\begin{array}{c}\mathrm{CF}_{3} \mathrm{I} \text {, infrared } \\
\text { gas, } \nu\end{array}$ \\
\hline $\begin{array}{l}\omega_{1} \\
\omega_{68} \\
\omega_{3} \\
\omega_{4} \\
\omega_{79} \\
\omega_{25}\end{array}$ & $\begin{array}{c}c m^{-1} \\
1105, \nu_{\mathrm{Fs}} \\
1212, \nu_{\mathrm{Fs}} \\
781, \nu_{\mathrm{C} 1} \\
470, \delta_{\mathrm{Fs}} \\
563, \delta_{\mathrm{Fs}} \\
356, \delta_{\mathrm{Cl}}\end{array}$ & $\begin{array}{c}c m^{-1} \\
1085, \nu_{\mathrm{Fs}} \\
1206, \nu \mathrm{Fs} \\
761, \nu_{\mathrm{Br}} \\
348, \delta_{\mathrm{Fs}} \\
550, \delta_{\mathrm{Fs}} \\
\text { b } 180, \delta_{\mathrm{Br}}\end{array}$ & $\begin{array}{r}c m^{-1} \\
950 \\
1140 \\
730 \\
340 \\
580 \\
180\end{array}$ & $\begin{array}{c}c m^{-1} \\
1073, \nu_{\mathrm{F}} \\
1186, \nu_{\mathrm{F}} \\
740, \nu_{\mathrm{I}} \\
284, \delta_{\mathrm{F}} \\
550, \delta_{\mathrm{F}} \\
\mathrm{s} 163, \delta_{\mathrm{I}}\end{array}$ \\
\hline
\end{tabular}

a Predicted from combination and difference bands.

b Calculated value of Stepanov.

a bromine or iodine is to shift the corresponding vibrations to longer wavelengths. Except for $\delta_{\mathrm{Br}}$ and $\delta_{\mathrm{I}}$, there is little doubt in the assignments of the fundamentals of these two molecules.

Some difficulty was experienced in the assignment of the fundamentals of the molecule $\mathrm{CBr}_{2} \mathrm{~F}_{2}$ and $\mathrm{CBrClF}_{2}$. Five fundamentals appear at wave numbers less than $440 \mathrm{~cm}^{-1}$. The intensities of these bands are low. Furthermore, three of the bands, $\omega_{4}, \omega_{7}$, and $\omega_{9}$, overlap and could not be resolved. Nevertheless, provisional assignments have been made for $\mathrm{CBr}_{2} \mathrm{~F}_{2}$ and $\mathrm{CBrClF}_{2}$, based on a comparison with the Raman spectra of Glocker and Leader [6], the calculated values, and also the infrared values of the related halomethane $\mathrm{CCl}_{2} \mathrm{~F}_{2}$. The relationships among the three molecules can be seen from table 4. Five infrared fundamentals for $\mathrm{CBr}_{2} \mathrm{~F}_{2}$ were found, and these check well with the Raman spectra. The bands at 1088, 1150, 829, and 621 $\mathrm{cm}^{-1}$ are all very strong, but the band at $331 \mathrm{~cm}^{-1}$ measured in the liquid state is very weak. The five frequencies are all smaller in wave number than the five corresponding frequencies of $\mathrm{CCl}_{2} \mathrm{~F}_{2}$, as would be expected. The remaining frequencies $\omega_{4}, \omega_{9}$, $\omega_{5}$, and $\omega_{2}$ were too weak to be determined in the infrared, and consequently the Raman values have been accepted and classified. As the fundamentals $\omega_{4}, \omega_{7}$, and $\omega_{9}$ overlap, the assignments of these bands are doubtful.

$\mathrm{CBrClF}_{2}$ can be considered an isotopic molecule of either $\mathrm{CBr}_{2} \mathrm{~F}_{2}$ or $\mathrm{CCl}_{2} \mathrm{~F}_{2}$. Its fundamentals should be intermediate in value. This is seen to be the case for the four strong infrared bands at 1102,

TABLE 4. Comparison of the infrared fundamentals of dibromodifluoromethane and bromochlorodifluoromethane with the infrared values of dichlorodifluoromethane, the Raman values of dibromodifluoromethane, and the calculated values of bromochlorodifluoromethane.

\begin{tabular}{|c|c|c|c|c|c|}
\hline $\begin{array}{l}\text { Class ifi- } \\
\text { cation }\end{array}$ & $\begin{array}{l}\mathrm{CBr}_{2} \mathrm{~F}_{2} \text {, in- } \\
\text { frared gas, } \nu\end{array}$ & $\begin{array}{c}\mathrm{CBr}_{2} \mathrm{~F}_{2}, \\
\text { liquaid, } v\end{array}$ & $\begin{array}{c}\mathrm{CBrClF}_{2} \text {, } \\
\text { infrared } \\
\text { gas, } \nu\end{array}$ & $\begin{array}{c}\mathrm{CBrClF}_{2} \\
\text { calcu- } \\
\text { lated, } v\end{array}$ & $\begin{array}{l}\mathrm{CCl}_{2} \mathrm{~F}_{2} \text {, in- } \\
\text { frared gas, } \nu\end{array}$ \\
\hline & $\mathrm{cm}^{-1}$ & $\mathrm{~cm}^{-1}$ & $\mathrm{~cm}^{-1}$ & $\mathrm{~cm}^{-1}$ & $\mathrm{~cm}^{-1}$ \\
\hline$\omega_{1}$ & $1088, \nu_{\mathrm{Fa}}$ & 1077 & $1102, \nu_{\mathrm{Fs}}$ & 1070 & $1101, \nu_{\mathrm{Fg}}$ \\
\hline$\omega_{8}$ & $1150, \nu_{\mathrm{Fa}}$ & 1142 & $1150, \nu_{\mathrm{Fa}}$ & 1130 & $1159, \nu_{\mathrm{Fa}}$ \\
\hline$\omega_{6}$ & $829, \nu \mathrm{Bra}$ & 816 & $872, \nu \mathrm{C} 1$ & 790 & $906, \nu \mathrm{Cla}$ \\
\hline$\omega_{3}$ & $621, \nu \mathrm{Brs}$ & 623 & $648, \nu \mathrm{Br}$ & 640 & $667, \nu_{\mathrm{Cl}}$ \\
\hline$\omega_{4}$ & b $340, \delta \delta_{\mathrm{FB}}$ & 340 & a $400, \delta_{\mathrm{FB}}$ & 390 & в $455, \delta_{\mathrm{Fg}}$ \\
\hline$\omega_{7}$ & - $331, \delta$ F Bra & 330 & a $380, \delta_{\mathrm{F} \mathrm{Br}}$ & 350 & $437, \delta_{\mathrm{FCl}}$ \\
\hline$\omega_{9}$ & b $367, \delta$ F Brs & 367 & $440, \delta \mathrm{FCl}$ & 440 & $473, \delta_{\mathrm{FCls}}$ \\
\hline$\omega_{5}$ & b 282 , Tor. & 282 & a 300 , Tor. & 260 & b 318 , Tor. \\
\hline$\omega_{2}$ & b $165, \delta_{\mathrm{Br}}$ & 165 & a $200, \delta \mathrm{Br}$ & 200 & b $261, \delta \mathrm{Cl}_{\mathrm{E}}$ \\
\hline
\end{tabular}

a Predicted from combination and overtone bands and related molecules. b Raman values.
1150,872 , and $648 \mathrm{~cm}^{-1}$. The frequencies $\omega_{4}, \omega_{7}$, $\omega_{5}$, and $\omega_{2}$ were determined from the combination bands, from the calculated frequencies of Stepanov, and from the related molecules $\mathrm{CBr}_{2} \mathrm{~F}_{2}$ and $\mathrm{CCl}_{2} \mathrm{~F}_{2}$.

An examination of the band shapes in the cases of the two symmetric tops, $\mathrm{CBrF}_{3}$ and $\mathrm{CF}_{3} \mathrm{I}$, further confirms the assignments for these molecules. In both cases the vibrations $\omega_{1}, \omega_{2}$, and $\omega_{3}$ are of symmetry species $A_{1}$, and $\omega_{68}, \omega_{79}$, and $\omega_{25}$ are of species E. Species $A_{1}$ should show a strong central maximum, the transition moment being parallel to the top axis. Species E should lack such a feature and lead to perpendicular bands. A few bands in the spectra of these molecules have envelopes that clearly possess or do not possess a zero branch. In each case this is consistent with the assignments made. For example, in the case of $\mathrm{CF}_{3} \mathrm{I}, \omega_{3}$ at $13.5 \mu$, and $\omega_{1}$ at $9.32 \mu$ should and do have central maxima; $\omega_{68}$ at $8.44 \mu$ should not and does not have the characteristic $P, Q$, and $R$ structure.

For the asymmetric tops, this method is not quite as rewarding. For those molecules of point group $\mathrm{C}_{s}, \mathrm{CHBrF}_{2}$ and $\mathrm{CBrClF}_{2}$, symmetry considerations show that of the nine fundamental vibrations, three will be of type $\mathrm{C}$ (transition moment lying along the axis of greatest moment of inertia), and the remaining six will be hybrids (transition moment having components along the other principal axes of moment of inertia). The type $\mathrm{C}$ bands should possess strong central maxima, and the hybrid bands, central maxima of varying prominence. Due to the inability to distinquish the type of band unambiguously, it was felt that consideration of the band envelopes would contribute little.

The remaining molecule, $\mathrm{CBr}_{2} \mathrm{~F}_{2}$, is of point $\mathrm{C}_{2 \mathrm{v}}$. For this point group, there are three types of bands, $\mathrm{A}, \mathrm{B}$, and $\mathrm{C}$, with $\omega_{8}$ and $\omega_{9}$ being of the first type, $\omega_{1}, \omega_{2}, \omega_{3}$, and $\omega_{4}$ of the second, and $\omega_{6}$ and $\omega_{7}$ of the last. Type $\mathrm{A}$ and $\mathrm{C}$ bands can be expected to show strong central maxima; type B should exhibit central minima. It was possible to check several bands of this molecule, and in every case but one the assignments and band shapes are consistent. Some doubt, however, exists as to the band at $11.43 \mu$, classified as $\omega_{8}-\omega_{5}$. This is a type $\mathrm{C}$ band, but the separation between the $\mathrm{P}$ and $\mathrm{R}$ branches is great enough to indicate a type $\mathrm{A}$ band. If this be a type $\mathrm{A}$ band, a possible explanation lies in the spectrum of $\mathrm{CBrClF}_{2}$. In this spectrum a very strong band of the same shape occurs at the same wavelength. $\mathrm{CBr}_{2} \mathrm{~F}_{2}$, the least pure of the five molecules, may contain $\mathrm{CBrClF}_{2}$ as an impurity.

\section{References}

[1] G. Herzberg, Infrared and Raman spectra of polyatomic molecules (D. Van Nostrand \& Co., Inc., New York, N. Y., 1945).

[2] J. C. Decius, J. Chem. Phys. 16, 214 (1948).

[3] Earle K. Plyler and W. D. Benedict, J. Research NBS 47, 202 (1951) RP2245.

[4] K. W. F. Kohlrausch, Ramanspectren (Becker and Erler, Leipsig, 1943).

[5] B. I. Stepanov, Compt. Rend. N. S. Academie des Sciences. URSS 45, 56 (1944).

[6] G. Glocker and G. R. Leader, J. Chem. Phys. 7, (1939).

Washington, August 14, 1951. 